\title{
Apolipoprotein $\mathbf{J}$ and Alzheimer's amyloid $\boldsymbol{\beta}$ solubility
}

\author{
Etsuro MATSUBARA*, Claudio SOTO, Sam GOVERNALE, Blas FRANGIONE and Jorge GHISO† \\ Department of Pathology, New York University Medical Center, 550 First Avenue, Room TH 432, New York, NY 10016, U.S.A.
}

\begin{abstract}
Apolipoprotein $\mathbf{J}(\mathrm{apo} \mathbf{J})$ has been found associated with soluble amyloid $\beta(\mathrm{sA} \beta)$ in plasma and cerebrospinal fluid in normal individuals and co-deposited with fibrillar A $\beta$ in Alzheimer's cerebrovascular and parenchymal lesions. Although studies in vitro and in vivo indicate that apoJ is a major carrier protein for $\mathrm{sA} \beta$, its role in the fibrillogenesis process is not known. We report herein that apoJ in its native high-density lipoprotein lipidic environment is fully active to interact with $\mathrm{A} \beta$ peptides. Furthermore, apoJ prevents aggregation and polymerization of
\end{abstract}

synthetic $\mathrm{A} \beta$ in vitro. The interaction was stable for at least 14 days at $37^{\circ} \mathrm{C}$ in physiologic buffers, and the peptide retrieved after complex dissociation at low $\mathrm{pH}$ retained its inherent aggregation properties. In addition, the binding to apoJ protects synthetic $\mathrm{A} \beta$ from proteolytic degradation; both $\mathrm{A} \beta 1-42$ and $\mathrm{A} \beta 1-40$ were more resistant to proteolysis by trypsin and chymotrypsin when complexed to apoJ. The data suggest that the interaction may preclude $\mathrm{sA} \beta$ aggregation in biological fluids and point to a protecting role of apoJ for complexed $\mathrm{A} \beta$ species.

\section{INTRODUCTION}

Amyloid $\beta$ (A $\beta)$, the major constituent of the fibrils deposited into senile plaques and cerebral blood vessels of patients with Alzheimer's disease (AD) and related disorders, is also normally present in body fluids as a soluble component $(\mathrm{sA} \beta)$ and is secreted by cells in culture (reviewed in [1]). The $\mathrm{A} \beta$ peptide extracted from senile plaques of AD patients is mainly $42-44$ amino acids long [2-4], whereas the vascular amyloid is primarily shorter at the C-terminus (39-40 amino acids) [5]. A $\beta 1-40$ is also the major form of $\mathrm{sA} \beta$, as determined by amino acid sequence analysis [6], although studies employing affinity chromatography, sequence analysis and laser desorption MS identified minor sA $\beta$ sequences with heterogeneity and length similar to the $\mathrm{A} \beta$ components deposited in senile plaques $[7,8]$. Therefore it is likely that these forms of $\mathrm{sA} \beta$ may represent the immediate precursors of the deposited $\mathrm{A} \beta$, linking $\mathrm{AD}$ with several types of systemic amyloidosis in which the soluble amyloid precursor circulates as a normal protein [9]. Based on the observations that under certain conditions and concentrations synthetic peptides homologous to $\mathrm{sA} \beta$ spontaneously polymerize in solution to form amyloid-like fibrils in vitro [10-13] and that the presence of cerebrospinal fluid (CSF) prevents fibril formation in vitro [14], we hypothesized the existence of plasma and/or CSF factors that maintain $\mathrm{sA} \beta$ in its soluble form, preventing its aggregation and suppressing its fibril-forming propensity [15]. In support to the first part of the hypothesis, we have identified what appears to be a major plasma and CSF carrier protein for sA $\beta$. The demonstration of a high-affinity interaction $\left(K_{\mathrm{d}}=2 \mathrm{nM}\right)$ between non-aggregated synthetic A $\beta 1-40$ and apolipoprotein $\mathbf{J}$ (apoJ) together with the identification of the complex apoJ-sA $\beta$ in vivo in CSF and the co-localization of $\mathrm{sA} \beta$ with apoJ-containing plasma high-density lipoproteins (HDL) suggest that apoJ plays an important role as a carrier molecule for $\mathrm{sA} \beta$ [15-17]. Albeit with less affinity, other proteins also have the ability to interact and form complexes with synthetic $\mathrm{A} \beta$ in vitro, among them apoE [18,19], apoA-I [20], apoA-II [20], $\alpha 1$-antichymotrypsin (ACT) [21] and transthyretin (TTR) [22]. Their biological importance as carrier molecules for $\mathrm{sA} \beta$ is unclear; however, certain apoE isoforms as well as ACT have been shown to modulate fibril formation of synthetic $\mathrm{A} \beta$ in experiments in vitro [21,23-25]. In addition, apoJ may be related not only to the transport of the soluble peptide in plasma but also to the delivery of sA $\beta$ through the blood-brain barrier. Studies in vivo performed in guinea pigs have demonstrated the existence of cerebrovascular permeability for A $\beta 1-40$ and human apoJ as well as for the apoJ-A $\beta 1-40$ complex $[26,27]$.

In order to test the hypothesis that the interaction with the carrier molecule maintains the solubility of the peptide, we have designed a simple protocol based on the complex dissociation properties at low $\mathrm{pH}$. Using synthetic $\mathrm{A} \beta$ peptides $(\mathrm{A} \beta 1-40$ and $\mathrm{A} \beta 1-42)$ and purified apoJ we were able to demonstrate by reverse-phase HPLC that after several days of incubation at physiologic $\mathrm{pH}$ and temperature (conditions that would induce the aggregation of more than $95 \%$ of the native peptide) the complex remained intact and soluble. After being released from the complex, the peptide retained its original structural characteristics and was able to self-aggregate with the same kinetics. Moreover, the complexed forms of the peptides appear to be protected from proteolytic degradation. The data indicate that, under the conditions tested, apoJ appears to prevent the aggregation and degradation of synthetic $\mathrm{A} \beta$ peptides in vitro.

\section{EXPERIMENTAL}

Synthetic peptides, proteins and antibodies

Peptides and proteins

Peptides DAEFRHDSGYEVHHQKLVFFAEDVGSNKGAIIGLMVVGGVV (A $\beta 1-40)$ and DAEFRHDSGYEVHHQKLV-

Abbreviations used: apoJ, apolipoprotein J; $A \beta$, amyloid $\beta$; sA $\beta$, soluble A $\beta$; AD, Alzheimer's disease; CSF, cerebrospinal fluid; ACT, $\alpha 1$ antichymotrypsin; TTR, transthyretin; HDL, high-density lipoproteins; A $\beta 1-42$ (agg), aggregated A $\beta 1-42 ;$ PBST, PBS containing $0.05 \%$ Tween-20; $\mathrm{ECL}$, enchanced chemiluminescence.

* Present address: Department of Neurology, Gunma University School of Medicine, 3-39-15 Showa-machi, Maebashy 371, Gunma, Japan.

$\dagger$ To whom correspondence should be addressed. 
FFAEDVGSNKGAIIGLMVVGGVVIA (A $\beta 1-42)$, homologous to residues $672-711$ and $672-713$ of $\beta$ PP770 respectively, were synthesized at the W. M. Keck Facility at Yale University using $N$-t-butyloxycarbonyl chemistry. Amino acids were coupled by activated esters and final deprotection/cleavage was performed using hydrogen fluoride. Peptide purification was carried out using a Vydac C18 reverse-phase column and a linear gradient of $0-80 \%$ acetonitrile in $0.05 \%$ trifluoroacetic acid. The final products were lyophilized and characterized by analytical reverse-phase HPLC, amino acid analysis, laser desorption MS and CD. A $\beta 1-40$ had mainly random coil conformation $(0 \% \alpha$-helix, $27.7 \% \beta$-sheet, $0.6 \% \beta$-turn and $71.7 \%$ random coil) whereas $\mathrm{A} \beta 1-42$ had predominantly $\beta$-sheet structure $(10 \% \alpha$-helix, $74.5 \% \quad \beta$-sheet, $6.4 \% \quad \beta$-turn and $9.1 \%$ random coil). A $1 \mathrm{mg} / \mathrm{ml}$ stock solution in $50 \%$ acetonitrile of either $\mathrm{A} \beta 1-40$ or $\mathrm{A} \beta 1-42$ was prepared and frozen at $-80^{\circ} \mathrm{C}$ until use. Human plasma apoJ was purchased from Quidel (San Diego, CA, U.S.A.); ACT and TTR were obtained from Calbiochem (La Jolla, CA, U.S.A.). Recombinant apoE isoforms 2, 3 and 4 (apoE2, ApoE3 and apoE4) were obtained from PanVera (Madison, WI, U.S.A.). In all cases, protein purity was corroborated by SDS/PAGE and N-terminal sequence analysis.

\section{Antibodies}

Polyclonal anti-apoJ 1535 was prepared in 12-week-old New Zealand White rabbits using a synthetic peptide, QLNEQFNWVSELAN (homologous to positions 134-147 of the apoJ $\beta$-chain), coupled to keyhole limpet haemocyanin (Sigma; $\mathrm{St}$ Louis, MO, U.S.A.). After an initial injection of $250 \mu \mathrm{g}$ of antigen dissolved in $0.5 \mathrm{ml}$ of sterile $0.15 \mathrm{M} \mathrm{NaCl}$ solution and emulsified with $0.5 \mathrm{ml}$ of monophospholipid A-synthetic trehalose dicorynomycolate (RIBI; Immunochem Research, Hamilton, MO, U.S.A.), rabbits were boosted every 15 days with the same amount of antigen dissolved in $0.15 \mathrm{M} \mathrm{NaCl}$ without adjuvant. After 8 weeks, test bleedings were obtained and analysed by ELISA for the presence of specific antibodies. Monoclonal IF12 antibody [anti-(apoJ $\alpha$-chain)] was a generous gift from Dr. N. H. Choi-Miura [28]; alkaline phosphataseconjugated goat $\mathrm{F}\left(\mathrm{ab}^{\prime}\right)_{2}$ anti-mouse IgG was purchased from BioSource (Camarillo, CA, U.S.A.); alkaline phophataselabelled streptavidin and horseradish peroxidase-labelled goat anti-mouse $\mathrm{F}\left(\mathrm{ab}^{\prime}\right)_{2}$ were obtained from Amersham (Arlington Heights, IL, U.S.A.); monoclonal 6E10 (anti-A $\beta 1-17)$ [29] was purchased from Senetek (Maryland Heights, MO, U.S.A.).

HDL

Human HDL were isolated by preparative gradient ultracentrifugation [16] from fresh human plasma obtained from normal healthy subjects, ages $25-40$ years, after a $10-12 \mathrm{~h}$ fast. In all cases, centrifugations were performed at $16^{\circ} \mathrm{C}$ at $100000 \mathrm{~g}$ using a Beckman Ti 50.2 rotor, and densities were adjusted to the necessary values with solid $\mathrm{KBr}$. Briefly, starting plasma was first depleted of very-low- and low-density lipoproteins by ultracentrifugation for $16 \mathrm{~h}$ at a density of $1.063 \mathrm{~g} / \mathrm{ml}$. Infranatants were re-adjusted to a density of $1.21 \mathrm{~g} / \mathrm{ml}$, and HDL were recovered after a $40 \mathrm{~h}$ centrifugation, extensively dialysed against $20 \mathrm{mM}$ Tris $/ \mathrm{HCl} / 150 \mathrm{mM} \mathrm{NaCl} / 1 \mathrm{mM}$ EDTA, $\mathrm{pH} 7.2$, and stored at $4{ }^{\circ} \mathrm{C}$. HDL were characterized by Tris/Tricine SDS/ PAGE (12.5\% gels), immunoblotting with specific antibodies directed against different apolipoproteins and electron microscopy [16]. The protein content of the HDL preparation was measured by the method of Bradford (BioRad; Hercules, CA, U.S.A.), employing BSA as a standard. The concentration of apoJ in HDL was estimated by a double-antibody sandwich
ELISA assay [28] using two anti-apoJ antibodies. Briefly, microtitre plates (Immulon 2, Dynatech Lab.; Chantilly, VA, U.S.A.) were precoated with polyclonal 1535 [anti-(apoJ $\beta$-chain)] and sequentially incubated with HDL samples followed by monoclonal IF12 antibody [anti-(apoJ $\alpha$-chain)], which had been conjugated to alkaline phosphatase, as described previously [28]. Colour was developed with $p$-nitrophenyl phosphate and evaluated at $405 \mathrm{~nm}$ on a 7520 Microplate Reader (Cambridge Technology; Watertown, MA, U.S.A.). Purified apoJ of known concentration (estimated by amino acid composition) was used as a standard.

\section{Solid-phase binding studies}

The interactions apo $\mathbf{J}-\mathbf{A} \beta 1-40$ and apo $\mathbf{J}-\mathbf{A} \beta 1-42$ were studied by ELISA, using A $\beta 1-40$, A $\beta 1-42$ and purified apoJ. Polystyrene microtitre plates (Immulon 2) were coated either with A $\beta 1-40$ or A $\beta 1-42$ (400 ng/100 $\mu$ l per well) in $0.1 \mathrm{M} \mathrm{NaHCO}_{3}, \mathrm{pH} 8.6$, for $2 \mathrm{~h}$ at $37^{\circ} \mathrm{C}$. Under these conditions, $10 \mathrm{ng}$ of $\mathrm{A} \beta 1-40$ and $9.6 \mathrm{ng}$ of A $\beta 1-42$ (representing $2.5 \%$ and $2.4 \%$, respectively, of the peptide offered) remained bound to the well, as determined by a modification of the Quantigold assay (Diversified Biotech; Boston, MA, U.S.A.). After blocking with $1 \%$ BSA, different concentrations of purified apoJ $(0-62.5 \mathrm{nM} ; 100 \mu \mathrm{l} /$ well $)$ in $20 \mathrm{mM}$ phosphate/150 mM NaCl at different $\mathrm{pH}(7.4,6.0$ and 5.0) were added to $\mathrm{A} \beta 1-40$ - or $\mathrm{A} \beta 1-42$-coated wells and incubated for $3 \mathrm{~h}$ at $37^{\circ} \mathrm{C}$. Bound apoJ was detected with monoclonal IF12, followed by alkaline phosphatase-conjugated goat $\mathrm{F}\left(\mathrm{ab}^{\prime}\right)_{2}$ anti-mouse $\operatorname{IgG}(1: 3000)$. The reaction was developed for $30 \mathrm{~min}$ with $p$-nitrophenyl phosphate in diethanolamine buffer (BioRad), stopped with $0.4 \mathrm{M} \mathrm{NaOH}$, and quantified at $405 \mathrm{~nm}$. Nonspecific binding was determined using BSA-coated wells and/or omitting apoJ in the assay. Binding data were analysed by nonlinear regression with the aid of curve-fitting software (GraphPad Prism Version 1.03, GraphPad Software; San Diego, CA, U.S.A.).

\section{Solid-phase inhibition assays}

Competitive inhibition of biotin-labelled apoJ binding to $A \beta 1-40$ and A $\beta 1-42$

A $100 \mu \mathrm{g}$ portion of apoJ was biotinylated with sulpho-NHS biotin (Pierce; Rockford, IL, U.S.A.) according to the manufacturer's specification; biotin-labelled apoJ was separated from free biotin by chromatography over Sephadex G-10 (Pharmacia; Piscataway, NJ, U.S.A.) equilibrated in $20 \mathrm{mM}$ phosphate/ $150 \mathrm{mM} \mathrm{NaCl}$, pH 7.2 (PBS). Increasing concentrations $(0-1750 \mathrm{nM})$ of either native unlabelled apoJ or HDL-apoJ were co-incubated with $25 \mathrm{nM}$ of biotin-labelled apoJ in PBS at different $\mathrm{pH}(7.4,6.0$ and 5.0) in $\mathrm{A} \beta 1-40$ - or $\mathrm{A} \beta 1-42$-coated wells (400 ng/well) for $3 \mathrm{~h}$ at $37^{\circ} \mathrm{C}$. Bound biotinylated apoJ was detected with alkaline phophatase-labelled streptavidin $(1: 1000)$ and evaluated as described above.

\section{Competitive inhibition of apoJ binding to $A \beta 1-40$ and $A \beta 1-42$}

Competitive inhibition assays were performed with apoE2, apoE3, apoE4, ACT and TTR. Solutions $(0-2500 \mathrm{nM})$ of the various competitors were co-incubated with $25 \mathrm{nM}$ of apoJ in A $\beta 1-40$ - or A $\beta 1-42$-coated wells (400 ng/well) for $3 \mathrm{~h}$ at $37^{\circ} \mathrm{C}$ at different $\mathrm{pH}(7.4,6.0$ and 5.0). Bound apoJ was determined with monoclonal IF12 followed by alkaline phosphatase-conjugated goat $\mathrm{F}\left(\mathrm{ab}^{\prime}\right)_{2}$ anti-mouse IgG and developed with $p$-nitrophenyl phosphate in diethanolamine buffer, as described above. 


\section{Complex characterization}

\section{Non-SDS/PAGE}

The apoJ-A $\beta 1-42$ complex was prepared by incubation of $2.2 \mu \mathrm{mol}$ of apoJ with $2.2 \mu \mathrm{mol}$ of $\mathrm{A} \beta 1-42$ in $0.1 \mathrm{M}$ Tris $/ \mathrm{HCl}$, $\mathrm{pH} 7.4$, for $4 \mathrm{~h}$ at $37^{\circ} \mathrm{C}$. The complex was separated on native $8 \%$ non-SDS/PAGE [30], transferred to poly(vinylidene difluoride) membranes (Immobilon P, Millipore; Milford, MA, U.S.A.), using 3-cyclohexylamino-1-propanesulphonic acid, $\mathrm{pH} 11$, containing $10 \%(\mathrm{v} / \mathrm{v})$ methanol and $0.1 \%$ SDS, stained with Coomassie Brilliant Blue; and the protein bands were excised and sequenced on a 477A protein sequencer (Applied Biosystems; Foster City, CA, U.S.A.), as described previously [17].

\section{Immunoblot analysis}

Aggregated A $\beta 1-42[\mathrm{~A} \beta 1-42(\mathrm{agg})]$ was prepared as follows: $50 \mu \mathrm{g}$ of the synthetic peptide was dissolved in $100 \mu \mathrm{l}$ of PBS and incubated at $37^{\circ} \mathrm{C}$ for different periods of time $(0-72 \mathrm{~h})$. Incubation was terminated by the addition of SDS sample buffer and 5 min boiling. For immunoblot detection, apoJ-A $\beta 1-42$ and apoJ-A $\beta 1-42(\mathrm{agg})$ complexes were prepared under identical conditions, using $2.2 \mu \mathrm{mol}$ of apoJ and $2.2 \mu \mathrm{mol}$ of either fresh or aggregated peptide. After $4 \mathrm{~h}$ of incubation at $37^{\circ} \mathrm{C}$, the complexes were separated on Tris/Tricine SDS/PAGE $(10 \%$ gels) and electroblotted on to nitrocellulose membrane (BioRad) using the same conditions described above. Membranes were blocked for $1 \mathrm{~h}$ with $5 \%$ low-fat dried milk in PBS containing $0.05 \%$ Tween-20 (PBST) and incubated overnight with monoclonal 6E10 (1:500), followed by horseradish peroxidase-labelled goat anti-mouse $\mathrm{F}\left(\mathrm{ab}^{\prime}\right)_{2}(1: 2000)$. Immunoblots were observed with an enhanced chemiluminescence (ECL) detection kit and exposed to Hyperfilm ECL (Amersham). The resulting bands were scanned on a PDI densitometer and evaluated with the Quantity One (Ver. 2.4) image analysis software (PDI; Huntington Station, NY, U.S.A.).

\section{Ligand blotting analysis}

In a separate set of experiments, the binding of apoJ to native and 72-h-aggregated A $\beta 1-42$ was studied by ligand-blotting analysis. Peptide aliquots (10 $\mu \mathrm{g}$ each) were separated in Tris/ Tricine SDS/PAGE (10\% gels) and transferred to nitrocellulose membranes as described above. After blocking for $1 \mathrm{~h}$ with $5 \%$ low-fat dried milk in PBST, half of the gel was reacted with monoclonal $6 \mathrm{E} 10($ anti-A $\beta$ ) and the other half was incubated for $3 \mathrm{~h}$ at $37^{\circ} \mathrm{C}$ with $20 \mu \mathrm{g}$ of apoJ in PBS followed by monoclonal IF12 (anti-apoJ). Bound antibodies were observed with alkaline phosphatase-labelled goat $\mathrm{F}\left(\mathrm{ab}^{\prime}\right)_{2}$ anti-mouse IgGs $(1: 3000)$ followed by 5-bromo-4-chloroindol-3-yl phosphate and Nitroblue Tetrazolium (Kirkegaard and Perry, Gaithersburg, MD, U.S.A.).

\section{Complex purification}

The stability of the apoJ-A $\beta 1-42$ complex at different $\mathrm{pH}$ was studied by affinity chromatography [15]. Briefly, synthetic A $\beta$ affinity matrices were allowed to interact in batch with $10 \mathrm{ml}$ of plasma at $37^{\circ} \mathrm{C}$ for $3 \mathrm{~h}$. After extensive washes to remove unbound proteins, bound components were eluted with $100 \mathrm{mM}$ phosphate buffers ( $\mathrm{pH} 7.4,6.5,6.0,5.5$ and 5.0), $100 \mathrm{mM}$ acetate buffers ( $\mathrm{pH} 4.5,4.0,3.5$ and 3.0$)$ or acetic acid $(\mathrm{pH} 2.5)$. The elution profile was monitored by absorbance at $280 \mathrm{~nm}$, and bound apoJ was identified by SDS/PAGE and N-terminal sequence analysis, as described above.
For purification of the apoJ-A $\beta 1-42$ complex, a modified reverse-phase HPLC was employed, using a Vydac C4 microbore column (214 TP 52, $0.21 \mathrm{~cm} \times 25 \mathrm{~cm}$; The Separations Group, Hesperia, CA, U.S.A.) and a $25 \mathrm{~min} 3-70 \%$ linear gradient of acetonitrile in water, $\mathrm{pH} 3.1$ (adjusted with trifluoroacetic acid), at a flow rate of $0.2 \mathrm{ml} / \mathrm{min}$. The elution profile was monitored at $214 \mathrm{~nm}$. The peaks obtained from reverse-phase HPLC were separated by electrophoresis and electroblotted on to nitrocellulose to identify the complex apoJ-A $\beta 1-42$ by immunoblot. Membranes were blocked for $1 \mathrm{~h}$ with $5 \%$ low-fat dried milk in PBST and incubated overnight with either monoclonal 6 E10 or monoclonal IF12 at 1:500 dilution, followed by horseradish peroxidase-labelled goat anti-mouse $\mathrm{F}\left(\mathrm{ab}^{\prime}\right)_{2}(1: 2000)$. Immunoblots were observed with an ECL detection kit and exposed to Hyperfilm ECL.

\section{Aggregation assays}

Stock solution of A $\beta 1-42$ was prepared in $50 \%$ acetonitrile, and its concentration was determined by amino acid analysis. Portions of this stock $(5 \mu \mathrm{g})$ were lyophilized, and incubations were started by adding $50 \mu \mathrm{l}$ of $0.1 \mathrm{M}$ Tris $/ \mathrm{HCl}, \mathrm{pH} 7.4$, with or without apoJ $(5 \mu \mathrm{g})$ at $37^{\circ} \mathrm{C}$. The degree of $\mathrm{A} \beta 1-42$ aggregation was monitored at different time points ( $0-14$ days) by measuring the peptide that remained in solution after centrifugation at $16000 \mathrm{~g}$ for $5 \mathrm{~min}$. The supernatants were analysed by reversephase HPLC, using a Vydac C4 microbore column (214 TP 52; $0.21 \mathrm{~cm} \times 25 \mathrm{~cm})$ on a $25 \mathrm{~min}$ linear gradient of $3-70 \%$ acetonitrile containing $0.1 \%$ trifluoroacetic acid $(\mathrm{pH} 2.1$; dissociating conditions for the apoJ-A $\beta$ complex). A $\beta 1-42$ was eluted from the column at $58 \%$ acetonitrile ( 19 min retention time). The area of the peak was used in order to estimate the percentage of the non-sedimentable peptide.

In separate experiments, we tested the aggregation properties of the peptide $\mathrm{A} \beta 1-42$ following its dissociation from the complex with apoJ. A $\beta 1-42$ purified by reverse-phase HPLC at $\mathrm{pH} 2.1$ from a 24 h-incubated complex was lyophilized, resuspended in

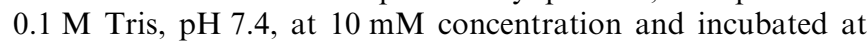
$37^{\circ} \mathrm{C}$ for $24 \mathrm{~h}$ and $72 \mathrm{~h}$ in the absence of apoJ. Freshly dissolved A $\beta 1-42$ was used as a control. The degree of aggregation was assessed by reverse-phase HPLC after centrifugation as described above.

\section{CD studies}

Changes in the secondary structure of $\mathrm{A} \beta 1-42$ were evaluated by CD measurements. Spectra in the far UV $(260-190 \mathrm{~nm})$ of A $\beta 1-42$ either freshly dissolved or recovered by HPLC from its complex with apoJ were recorded at $24{ }^{\circ} \mathrm{C}$ with a Jasco J-720 spectropolarimeter (Jasco Corp.; Tokyo, Japan), using a cell path of $0.1 \mathrm{~cm}$ at a peptide concentration of $0.3 \mathrm{mg} / \mathrm{ml}$. Results were expressed in terms of mean residue ellipticity $\left(\mathrm{deg} \cdot \mathrm{cm}^{2} \cdot \mathrm{dmol}^{-1}\right)$. CD data were analysed by the Lincomb algorithm [31] to obtain the percentages of the different secondary structure motifs.

\section{RESULTS AND DISCUSSION}

We have characterized the apoJ-A $\beta 1-42$ interaction by means of solid-phase ELISA experiments and compared the results with those obtained for the more soluble species A $\beta 1-40$. When increasing concentrations of apoJ were allowed to interact with a constant amount of immobilized peptide at physiologic $\mathrm{pH}$ and temperature, a specific, saturable binding was observed. The binding curve fitted to a rectangular hyperbola enabled the calculation of the dissociation constant $K_{\mathrm{d}}$ of $4.6 \times 10^{-9} \mathrm{M}$ (Figure 
A

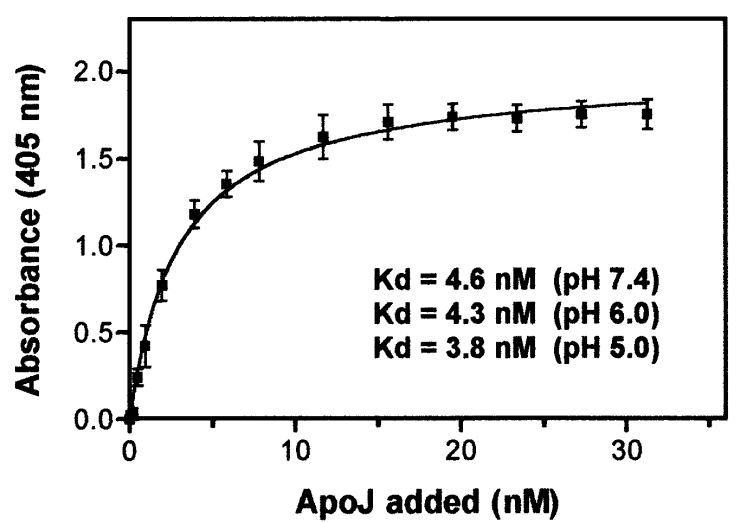

C

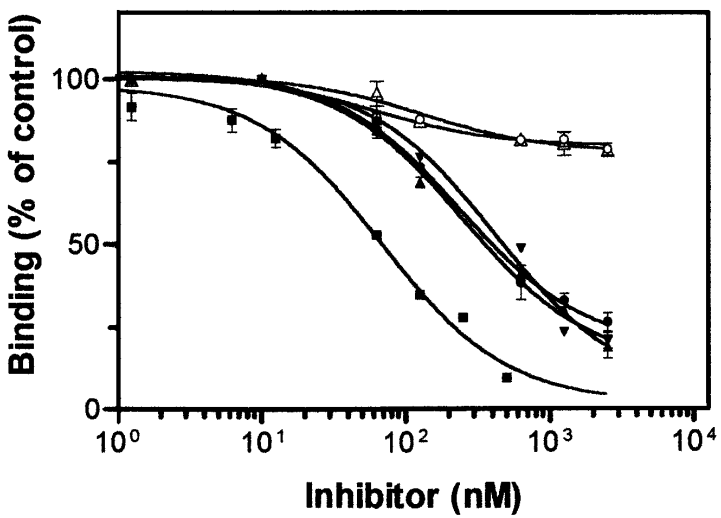

B

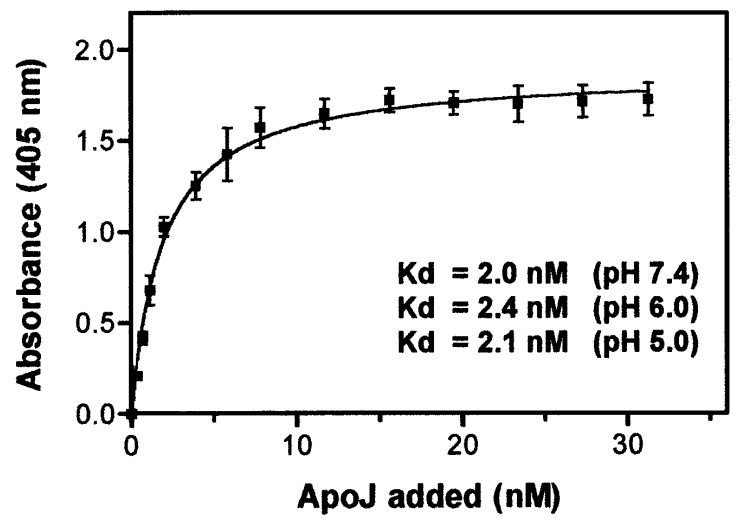

D

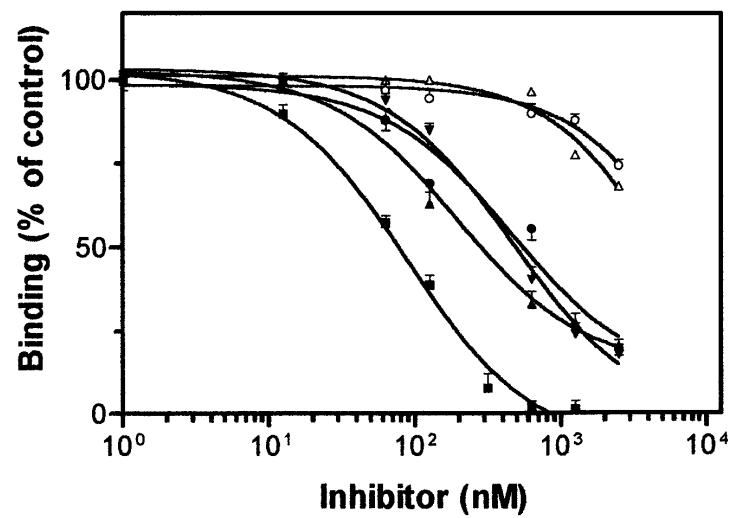

Figure 1 ApoJ-A $\beta(A \beta 1-42$ and $A \beta 1-40)$ interaction at variable $\mathrm{pH}$

(A, B) Saturation curves. Variable concentrations of apo $(0-62.5 \mathrm{nM})$ were incubated with either $\mathrm{A} \beta 1-40-(\mathbf{A})$ or $\mathrm{A} / 31-42-\mathrm{coated}$ wells $(\mathbf{B})$ at variable $\mathrm{pH}(7.4,6.0$ and 5.0$)$ for $3 \mathrm{~h}$ at $37^{\circ} \mathrm{C}$. Bound apoJ was detected with monoclonal IF12 and alkaline phosphatase-labelled anti-mouse as described in the Experimental section. The curves shown were both obtained at pH 7.4. Each point represents the mean ( \pm 2 S.D.) of five independent duplicate experiments. (C, D) Competitive inhibition of the apoJ-A $\beta 1-40$ (C) and apoJ-A $\beta 1-42$ (D) complex formation by amyloidassociated proteins. ApoJ (25 nM) was combined with variable concentrations (0-2500 nM) of apoE2 ( $\mathbf{A})$, apoE3 $(\boldsymbol{O})$, apoE4 ( $)$, ACT $(\triangle)$ or TTR $(\bigcirc)$, and co-incubated with either A $\beta 1-40$ (C) or A $\beta 1-42$-coated wells (D). Bound apoJ was determined as described in the Experimental section. For apoJ self-competition ( $\mathbf{\square})$, native apoJ (0-1136 nM) was co-incubated with $25 \mathrm{nM}$ biotin-labelled apoJ in either A $\beta 1-40$ - or A $\beta 1-42$-coated wells. Bound biotin-labelled apoJ was detected with alkaline phosphatase-labelled streptavidin. Data represent the mean ( \pm 2 S.D.) of three independent duplicate experiments.

1A). The interaction was not affected by $\mathrm{pH}$ variations within the range of 5.0-7.4; the corresponding saturation curves (not shown) and the calculated $K_{\mathrm{d}}$ values at $\mathrm{pH} 6.0(4.3 \mathrm{nM})$ and $5.0(3.8 \mathrm{nM})$ were not different from the one obtained at $\mathrm{pH}$ 7.4. The $K_{\mathrm{d}}$ values for the apoJ-A $\beta 1-42$ interaction were the same order of magnitude as those calculated for apoJ binding to $\mathrm{A} \beta 1-40$ (Figure 1B): $2 \mathrm{nM}$ at $\mathrm{pH} 7.4$ [17], $2.4 \mathrm{nM}$ at $\mathrm{pH} 6.0$ and $2.1 \mathrm{nM}$ at $\mathrm{pH}$ 5.0. It is interesting to note that conformational changes can be induced in the $\mathrm{A} \beta$ peptides by modifying the $\mathrm{pH}$ [32]. We have observed the most dramatic changes when $\mathrm{A} \beta 1-40$ was used (the amount of $\beta$ sheet increased from $27.7 \%$ at $\mathrm{pH} 7.4$ to $64.03 \%$ at $\mathrm{pH} 5.0)$; $\mathrm{A} \beta 1-42$ already contained a high percentage of $\beta$ sheet at neutral $\mathrm{pH}(74.5 \%)$, and, therefore, lowering the $\mathrm{pH}$ resulted in minimal conformational changes in solution. In our experiments in vitro we did not find important differences in the apo $\mathrm{J}-\mathrm{A} \beta 1-40$ and $\mathrm{A} \beta 1-42$ binding activity when the $\mathrm{pH}$ was lowered to 5.0, suggesting either that the interaction is independent of the peptide conformation or that the immobilization to a solid phase induces peptide conformations that are not vulnerable to $\mathrm{pH}$ changes.
The specificity of the interaction was tested at physiologic $\mathrm{pH}$ by means of inhibition experiments using biotinylated apoJ at a concentration of $25 \mathrm{nM}$ (at which $85-90 \%$ saturation of both A $\beta 1-40$ - and A $\beta 1-42$-coated wells was achieved). As indicated in Figure $1(\mathrm{C})$, the binding of biotin-labelled apoJ to immobilized A $\beta 1-42$ was competitively inhibited by increasing concentrations of native apoJ. The data fitted into a one-site competition curve with a calculated value for half-maximal inhibition $\left(\mathrm{IC}_{50}\right)$ of

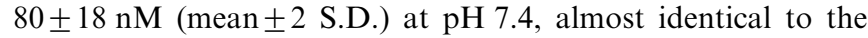
value $(77 \pm 15 \mathrm{nM})$ for the inhibition of the interaction between apoJ and $\mathrm{A} \beta 1-40$ (Figure 1D; [17]). In addition to apoJ, several other proteins have been implicated in binding interactions with $\mathrm{A} \beta$, among them apoE (isoforms 2, 3 and 4) [18,19], apoAI [20], ACT [21] and TTR [22]. Therefore competitive inhibition experiments of the apoJ-A $\beta 1-42$ complex formation by these proteins were also performed by ELISA. For comparison purposes, competitive inhibition assays for the complex formation between purified apoJ and $\mathrm{A} \beta 1-40$ were performed in parallel. Increasing concentrations of each competitor were mixed with constant amounts of apoJ and immediately added to $\mathrm{A} \beta 1-42-$ or $\mathrm{A} \beta 1-40$ - 


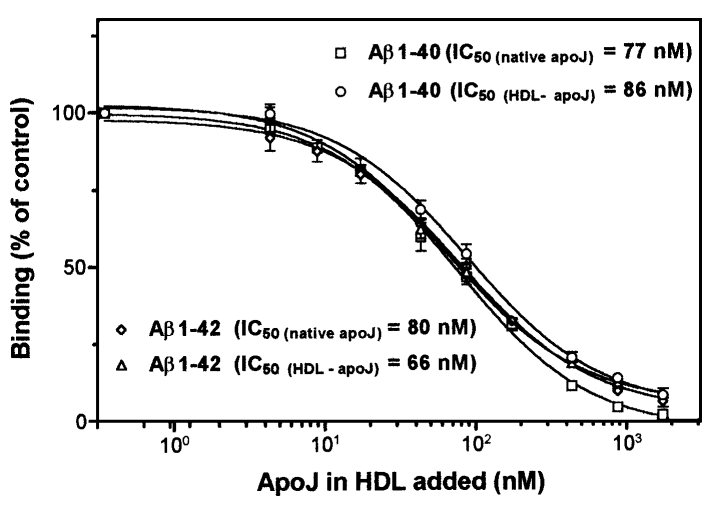

Figure 2 Self-inhibition of the apoJ-A $\beta$ complex formation by apoJ-HDL

Either purified apoJ or HDL particles containing apoJ (0-1750 nM apoJ) were co-incubated with $25 \mathrm{nM}$ biotin-labelled apoJ in either A $\beta 1-40$ - or A $\beta 1-42$-coated wells. Bound biotinylated apoJ was evaluated with alkaline phosphatase-labelled streptavidin as described in the Experimental section. Data represent the mean ( \pm 2 S.D.) of three independent duplicate experiments.

coated wells; after $3 \mathrm{~h}$ incubation at $37^{\circ} \mathrm{C}$, bound apoJ was detected with anti-apoJ antibody followed by alkaline phosphatase-labelled anti-mouse IgG. Figure 1(C) illustrates the corresponding competition curves in comparison with the apoJ self-inhibition determined by competitive inhibition of biotinlabelled apoJ binding to $\mathrm{A} \beta 1-42$ by unlabelled apoJ. None of the proteins tested exhibited higher affinity for A $\beta 1-42$ than apoJ did. The three apoE isoforms showed a similar affinity for $\mathrm{A} \beta 1-42$; the calculated $\mathrm{IC}_{50}$ values (mean \pm 2 S.D.) were $245 \pm 46 \mathrm{nM}$ (apoE4), 267 $\pm 39 \mathrm{nM}$ (apoE2) and $292 \pm 45 \mathrm{nM}$ (apoE3). The rest of the proteins assayed exhibited very low competitive effects, all in the $\mu$ molar range. Although with slightly lower affinity, a similar behaviour has been detected for A $\beta 1-40$ (Figure 1D) [17]; the competition curves distributed themselves into the same two groups, one composed of the apoE isoforms and the other of the rest of the proteins. As in the case of $\mathrm{A} \beta 1-42$, none of the proteins tested exhibited better affinity for $\mathrm{A} \beta 1-40$ than apoJ did. ApoE2 and apoE4 $\mathrm{IC}_{50}$ values were very close $(316 \pm 47$ and $335 \pm 49 \mathrm{nM}$ respectively), whereas apoE3 was somehow a less avid competitor $(508 \pm 44 \mathrm{nM})$, a behaviour also observed with $\mathrm{A} \beta 1-42$. It is important to note that the apoE isofoms used in the competition experiments were recombinant species expressed in Sf9 cells; therefore the effect that lipids may exert in the observed interaction is not known. An important source of variability in these experiments in vitro is undoubtedly related to the origin of apoE. The most significant variations have been found in products provided by different manufacturers, but inter-lot variability (in quality and quantity) within the same manufacturer has also been common. In the set of experiments described above, the same provider and the same lot were used. In this context we have found a lower $\mathrm{IC}_{50}$ value for apoE4 in competition experiments than our previously published data (335 $\mathrm{nM}$ versus $794 \mathrm{nM}$ [17]), differences that might be explained by the different source of apoE4 used in both cases.

In order to test the physiologic relevance of the data, competitive inhibition studies were performed using apoJ in its native HDL environment. HDL particles were purified from normal plasma using the well-established density ultracentrifugation methodology, characterized by gel electrophoresis, immunoblot analysis and electron microscopy [16], and the content of apoJ was estimated by a double-antibody sandwich ELISA assay, using purified apoJ as standard [28]. HDLs were mainly composed of apoAI and apoAII, but also contained apoCII, apoE, apoJ and apoAIV, as previously described [16]. Under the conditions tested, the apoJ concentration in our HDL preparation was estimated as $12.3( \pm 1.1) \mu \mathrm{g}$ per mg of HDL. As indicated in Figure 2, the competition curves virtually superimposed on one another and the corresponding calculated $\mathrm{IC}_{50}$ values for purified apoJ and HDL-apoJ were almost identical. The binding of biotin-labelled apoJ to immobilized A $\beta 1-42$ was competitively inhibited by increasing concentrations of apoJHDL; the calculated $\mathrm{IC}_{50}$ value $(66 \pm 19 \mathrm{nM})$ was within the same range as the one obtained with isolated apoJ $(80 \pm 18 \mathrm{nM})$. When $\mathrm{A} \beta 1-40$ was immobilized, the $\mathrm{IC}_{50}$ values obtained with apoJ-HDL and isolated apoJ were even closer $(86 \pm 20 \mathrm{nM}$ for apoJ-HDL versus $77 \pm 15 \mathrm{nM}$ for isolated apoJ). These results clearly indicate that apoJ, in its lipid environment of the HDL particle, is fully functional to interact with $\mathrm{sA} \beta$, supporting the physiological relevance of the interaction.

The decrease of $\mathrm{pH}$ from 7.4 to 5.0 did not affect significantly the measured binding affinity between apoJ and either $\mathrm{A} \beta 1-42$ or A $\beta 1-40$. However, our previous studies indicated that the complex could be dissociated at very low pH (below 3.0) [15]. In order to determine whether this property might be useful to purify the intact apoJ-A $\beta$ complex from its components, the stability of the complex with the $\mathrm{pH}$ was studied in more detail. Synthetic $\mathrm{A} \beta$ immobilized on to an affinity matrix was allowed to interact at physiologic $\mathrm{pH}$ with normal plasma for $3 \mathrm{~h}$ at $37^{\circ} \mathrm{C}$, essentially as described previously [15]. After removing all unbound proteins, elution of bound apoJ was carried out using a discontinuous $\mathrm{pH}$ gradient (from 7.4 to 2.5). The pertinent identification of apo $J$ in the different fractions was carried out by immunoblot analysis and corroborated via $\mathrm{N}$-terminal sequence analysis. As shown in Figure 3(A), apoJ remained bound to the affinity matrix even at $\mathrm{pH} 3.0$ and was completely eluted at $\mathrm{pH} 2.5$, indicating that the complex is stable in a wide $\mathrm{pH}$ range and that a narrow threshold below $\mathrm{pH} 3$ would cause its dissociation. Based on this concept, we have designed a simple protocol to isolate the apoJ-A $\beta 1-42$ complex from its components; after incubation of equal concentrations of both apoJ and $\mathrm{A} \beta 1-42$ for $4 \mathrm{~h}$ at $37^{\circ} \mathrm{C}$ (see the Experimental section for details), the mixture was separated on a $\mathrm{C} 4$ microbore column using a $25 \mathrm{~min} 3-70 \%$ linear gradient of acetonitrile in water, adjusted to $\mathrm{pH} 3.1$ with trifuoroacetic acid. A new peak eluting at $62 \%$ acetonitrile (Figure 3B, dashed line) contained the intact apoJ-A $\beta 1-42$ complex, as judged by immunoblot and sequence analyses. An $85 \mathrm{kDa}$ component was recognized by antibodies specific for both $\mathrm{A} \beta$ (4G8 and 6E10) and apo $\mathbf{J}$ in immunoblot analysis (results not shown), and $\mathrm{N}$ terminal amino acid sequence analysis after electroblotting retrieved the sequences DQTVSDNELQ, SLMPFSPYEP and DAEFRHDSGY, corresponding to the intact N-terminus of apoJ $\alpha$-chain, apoJ $\beta$-chain and $\mathrm{A} \beta$ respectively. When a similar aliquot of the complex was separated in the same column now equilibrated at $\mathrm{pH} 2.1$ (0.05\% trifluoroacetic acid), the complete dissociation of the complex in its components was observed; A $\beta 1-42$ eluted at $58 \%$ acetonitrile whereas apoJ had a longer retention time and was recovered with $65 \%$ acetonitrile (Figure $3 \mathrm{~B}$, continuous line). No peaks were detected at $62 \%$ acetonitrile. These results clearly indicate that the apoJ-synthetic A $\beta$ complex can be successfully isolated from its components by a $\mathrm{pH}-$ modified reverse-phase methodology.

We have previously reported that apoJ has higher affinity for monomeric A $\beta 1-40$ than for the aggregated peptide; this also applies for $\mathrm{A} \beta 1-42$. Complexes were formed by incubation of 

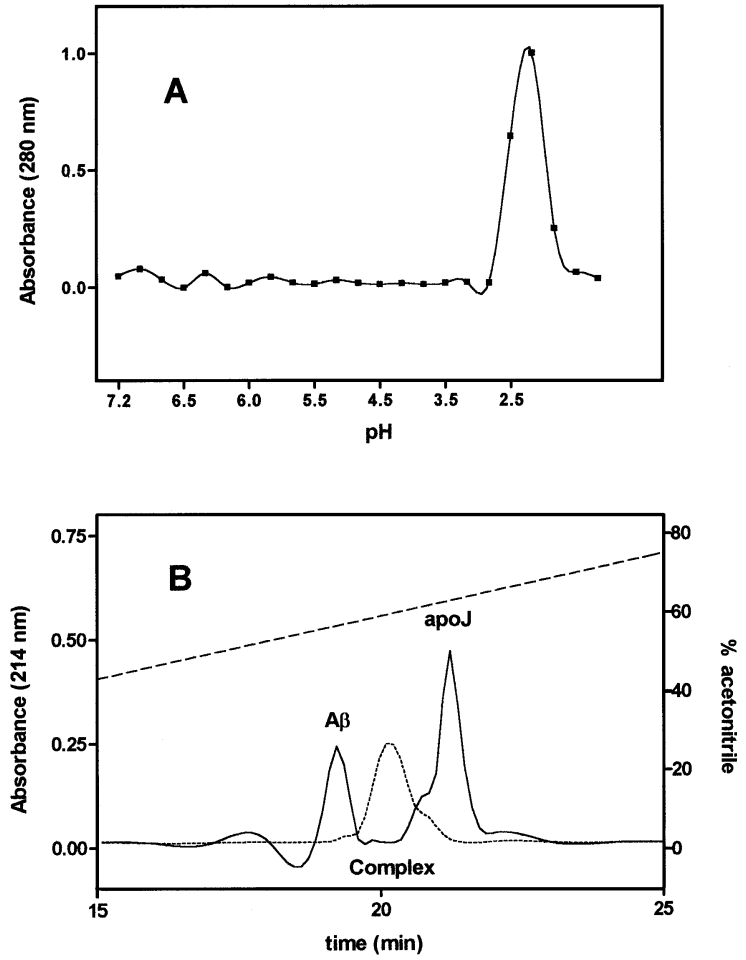

Figure 3 Complex dissociation by $\mathrm{pH}$

(A) Affinity chromatography. Synthetic A $\beta$-affinity matrices were allowed to interact with normal human plasma for $3 \mathrm{~h}$ at $37^{\circ} \mathrm{C}$. After washing off the column all the unbound proteins, elution of apoJ was carried out at discontinuous pH (from 7.4 to 2.5) and monitored by absorbance at $280 \mathrm{~nm}$. The presence of apoJ in the different fractions was determined by immunoblot analysis and confirmed by N-terminal sequence analysis. (B) Reverse-phase HPLC. apoJA $\beta 1-42$ complex was subjected to reverse-phase HPLC under either dissociating (pH 2.1) or non-dissociating ( $\mathrm{pH} 3.1$ ) conditions. Proteins were eluted using a $25 \mathrm{~min} 3-70 \%$ linear gradient of acetonitrile $(--)$. Retention times for dissociating conditions: $A \beta 1-42=19$ min (58\% acetonitrile); apoJ $=22 \mathrm{~min}$ (65\% acetonitrile). Under non-dissociating conditions, the complex was recovered at $62 \%$ acetonitrile (retention time $=20.5 \mathrm{~min}$ ). Identification was carried out by immunoblot and $\mathrm{N}$-terminal sequence analysis.

apoJ with fresh and aggregated $\mathrm{A} \beta 1-42$ and observed via immunoblot analysis after SDS/PAGE, using monoclonal 6E10 (anti-A/1-17), as indicated in Figure 4 (left panel). Scanning densitometry of the fluorograms revealed that apoJ formed 8-fold more $85 \mathrm{kDa}$ complex with the fresh peptide (Figure 4, left panel, lane 4) than with the 24-h-aggregated $\mathrm{A} \beta 1-42$ (lane 5). In addition, the polymerization of the peptide was influenced by the presence of apoJ. The aggregation pattern of the freshly prepared A $\beta 1-42$ (Figure 4, left panel, lane 1) remained unmodified following $24 \mathrm{~h}$ incubation with apoJ (lane 4), as judged by the similar amount of dimers present and the absence of other higher-molecular-mass polymers. In contrast, the peptide incubated alone for the same period of time under identical conditions showed increased polymerization (Figure 4, left panel, lane 2). In order to test whether apoJ has any effect on the peptide polymerization once the aggregation process has started, apoJ was added to the $24 \mathrm{~h}$-pre-aggregated peptide and incubated for another $24 \mathrm{~h}$. As seen in Figure 4 (left panel), lane 5, the degree of A $\beta 1-42$ aggregation remained unmodified and its pattern resembled the one indicated in lane 2 . However, the same peptide incubated in the absence of apoJ (Figure 4, left panel, lane 3) exhibited further polymerization, as indicated by the amount of dimers and higher-molecular-mass oligomers. These results

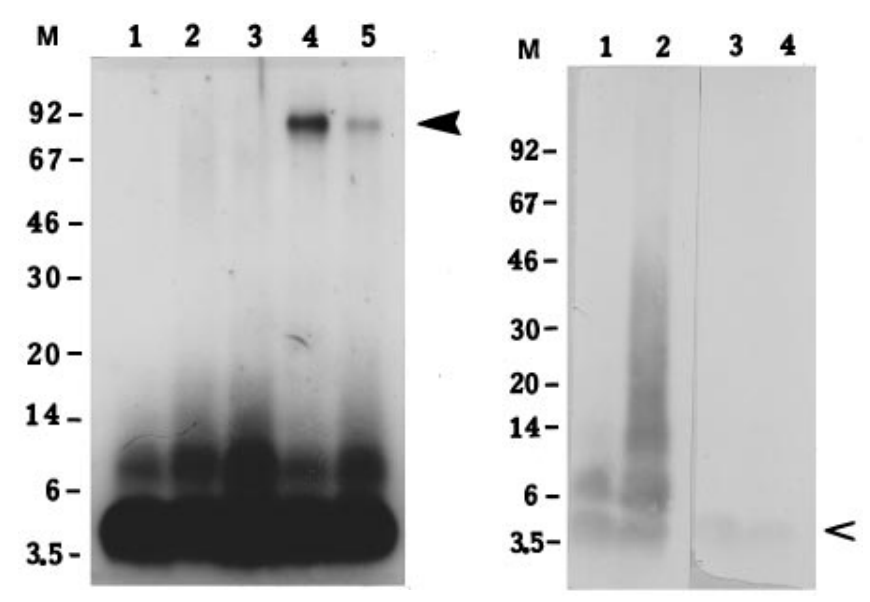

Figure 4 Immunodetection of the apoJ-A $\beta 1-42$ complex formed with fresh and/or aggregated peptide

(Left) SDS/PAGE. apoJ-A $\beta 1-42$ and apoJ-A $\beta 1-42$ (agg) complexes were prepared in PBS, mixing $2.2 \mu \mathrm{mol}$ of apoJ and $2.2 \mu \mathrm{mol}$ of either fresh or 24 -h-aggregated A $\beta 1-42$. After incubation, samples were separated by Tris/Tricine SDS/PAGE (10\% gel), immunoblotted with monoclonal 6 E10 (anti-A $\beta 1-17$ ) and observed with horseradish peroxidase-labelled anti-mouse IgG followed by ECL. Lane 1, fresh A $\beta 1-42$ (100 ng); lane 2, 24 h-heat-aggregated A $\beta 1-42$ $(100 \mathrm{ng})$; lane 3, $48 \mathrm{~h}$-heat-aggregated $\mathrm{A} \beta 1-42(100 \mathrm{ng})$; lane 4, apoJ-fresh $A \beta 1-42$ complex (100 ng); lane 5, apoJ-24-h-aggregated A $\beta 1-42$ complex (100 ng). M, molecularmass markers (phosphorylase b, $92 \mathrm{kDa}$; BSA, $67 \mathrm{kDa}$; ovalbumin, $46 \mathrm{kDa}$; carbonic anhydrase, $30 \mathrm{kDa}$; trypsin inhibitor, $20 \mathrm{kDa}$; lysozyme, $14 \mathrm{kDa}$; aprotinin, $6 \mathrm{kDa}$; and insulin $\beta$-chain, $3.5 \mathrm{kDa}$ ). Arrowhead indicates apoJ-A $\beta 1-42$ complex. (Right) Ligand blot analysis. Freshly prepared (lanes 1 and 3 ) and $72 \mathrm{~h}$-heat-aggregated A $\beta 1-42$ (lanes 2 and 4 ) were subjected to electrophoretic separation by Tris/Tricine SDS/PAGE (10\% gel) and transferred to a nitrocellulose membrane. Lanes 1 and 2 were immunoblotted with monoclonal 6 E10 followed by alkaline phosphatase-labelled anti-mouse IgG and developed with 5-bromo-4-chloroindol3 -yl phosphate and Nitroblue Tetrazolium. Lanes 3 and 4 were incubated with purified apoJ for $3 \mathrm{~h}$ at $37^{\circ} \mathrm{C}$ and $16 \mathrm{~h}$ at $4{ }^{\circ} \mathrm{C}$. Bound apoJ was detected with monoclonal IF12 [anti-(apoJ $\alpha$-chain)] and observed as described above. $\mathrm{M}$, molecular weight markers, as in the left panel. Open arrowhead, apoJ-A $\beta 1-42$ complex.

suggest that apoJ might exert a protective effect on $\mathrm{sA} \beta$, preventing its oligomerization and aggregation.

To confirm that the binding interaction takes place with the monomeric and not with the polymeric forms of $\mathrm{A} \beta 1-42$, we have additionally performed ligand-blotting analysis. Freshly dissolved and 24-h-aggregated A $\beta 1-42$ were fractionated by SDS/PAGE, transferred to a poly(vinylidine difluoride) membrane and allowed to interact with apoJ for $3 \mathrm{~h}$ at $37^{\circ} \mathrm{C}$. Bound apoJ was detected with monoclonal anti-apoJ (IF12) followed by alkaline phosphatase-labelled anti-mouse IgG. As indicated in Figure 4 (right panel), apoJ bound only to the monomeric forms of the peptide present in the fresh (lane 3) and 24-h-aggregated (lane 4) preparations. Dimers and higher-molecular-mass components of $\mathrm{A} \beta 1-42$ (evidenced by immunoreactivity with monoclonal 6E10; Figure 4, right panel, lanes 1 and 2) did not exhibit visible binding, although the polymeric forms were quantitatively more important than the monomers in the 24-h-aggregated sample. These findings correlate with our previously reported results for the apoJ-A $\beta 1-40$ interaction; inhibition experiments carried out with freshly prepared and 24-h-aggregated A $\beta 1-40$ indicated that the aggregated peptide exhibited 5-fold less relative affinity to form complexes with apoJ $\left(\mathrm{IC}_{50}=315 \mathrm{nM}\right)$ than with the fresh peptide $\left(\mathrm{IC}_{50}=63 \mathrm{nM}\right)$ [17].

To test further the influence that apoJ exerts in the aggregation process of the $\mathrm{A} \beta$ peptides, we performed a series of HPLC 
A

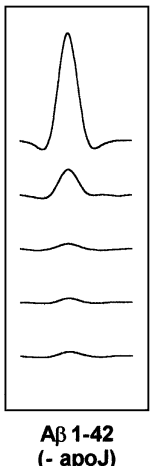

B

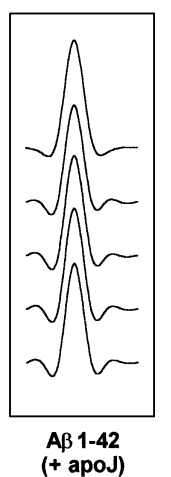

\section{Figure 5 ApoJ prevents the $A \beta 1-42$ self-aggregation}

$\mathrm{A} \beta 1-42$ (5 $\mu \mathrm{g}$ aliquots) was incubated at $37^{\circ} \mathrm{C}$ in PBS, $\mathrm{pH} 7.4$, for different periods of time in the presence and the absence of apoJ $(5 \mu \mathrm{g})$. After removing aggregates by centrifugation, the complex was dissociated at pH 2.1 and separated in reverse-phase HPLC as described for Figure 3(B). The amount of the peptide retrieved at $19 \mathrm{~min}$ (58\% acetonitrile) was evaluated by the area of the eluted peak. (A) A $\beta 1-42$ incubated in the absence of apoJ; (B) A $\beta 1-42$ incubated in the presence of apoJ.

experiments using the highly aggregable A $\beta 1-42$, taking advantage of the above-mentioned indication that the intact complex can be purified by reverse-phase HPLC at $\mathrm{pH} 3.1$ and dissociated into its own components at $\mathrm{pH}$ 2.0. Identical aliquots of freshly dissolved A $\beta 1-42$ were incubated at $37^{\circ} \mathrm{C}$ for different periods of time in the absence or the presence of apoJ at physiologic $\mathrm{pH}$. After incubation, the aggregated components were removed from the soluble forms by centrifugation, and the amount of peptide that remained in solution was determined on reverse-phase HPLC at $\mathrm{pH} 2.0$ (conditions that completely dissociated the complex). The soluble peptide was recovered at its characteristic retention time (19 $\mathrm{min}, 58 \%$ acetonitrile), and the amount was estimated by the area of the eluted peak. As indicated in Figure 5(A), A $\beta 1-42$ aggregated very fast; $23.5 \%$ of the peptide stayed in solution after a $24 \mathrm{~h}$ incubation and only $4 \%$ was left soluble after $48 \mathrm{~h}$, an amount that remained almost constant throughout the rest of the experiment; even after 14 days at $37{ }^{\circ} \mathrm{C}, 4 \%$ of the peptide was detected in the soluble fraction. When identical aliquots of $\mathrm{A} \beta 1-42$ were incubated in the presence of apoJ, the amount of peptide recovered in the HPLC under dissociating conditions was almost the same as the amount retrieved from a freshly prepared complex. For example, after $72 \mathrm{~h}, 96 \%$ of the peptide remained in solution (Figure 5B) whereas in the absence of apoJ, only $4 \%$ was found in its soluble form (Figure 5A). Moreover, $87 \%$ of the $\mathrm{A} \beta 1-42$ incubated with apoJ was still soluble after 14 days at $37^{\circ} \mathrm{C}$. These results indicate that under the conditions tested, the presence of apoJ prevents the aggregation of $\mathrm{A} \beta 1-42$ in vitro.

In order to test whether $\mathrm{A} \beta 1-42$ retained its native properties after being complexed to apoJ, A $\beta 1-42-$ apoJ complexes were incubated for $72 \mathrm{~h}$ at $37^{\circ} \mathrm{C}$ (conditions that would result in $96 \%$ aggregation of the peptide in the absence of apoJ); after centrifugation to remove any aggregates, the soluble complex was dissociated at $\mathrm{pH} 2.0$ and both components, apoJ and A $\beta 1-42$, separated by HPLC. A $\beta 1-42$ recovered from the complex was incubated at $37{ }^{\circ} \mathrm{C}$ for different periods of time (up to $72 \mathrm{~h}$ ), centrifuged to separate newly formed aggregates and evaluated by reverse-phase HPLC in comparison with identical aliquots of freshly prepared $\mathrm{A} \beta 1-42$ as a control of non-

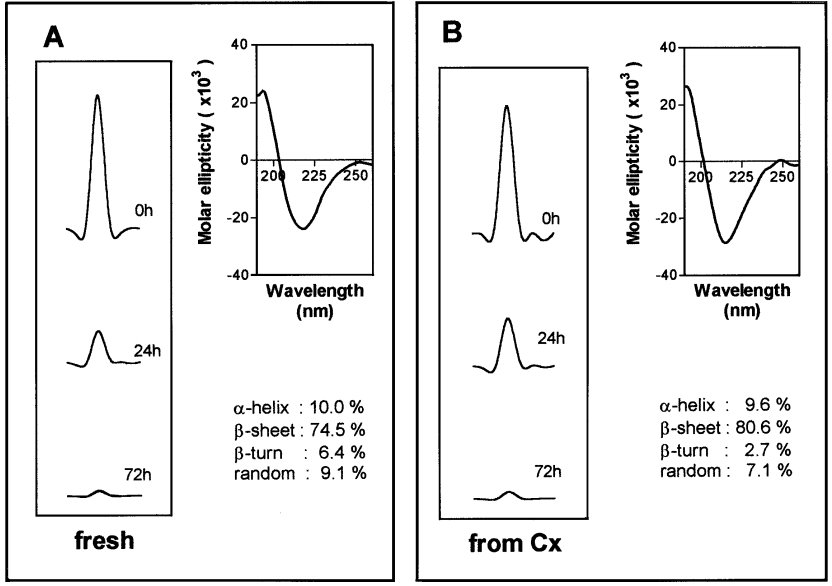

Figure $6 \quad A \beta 1-42$ aggregation properties

The aggregation characteristics of freshly dissolved $A \beta 1-42(\mathbf{A})$ were compared with those of the peptide retrieved from its complex (Cx) with apoJ after different periods of time (B). Evaluation was carried out as in Figure 5. CD spectra for both specimens were recorded (insets) and the respective molar ellipticity plots as well as the calculated secondary structure values are shown.

aggregation. As indicated in Figure 6(B), the peptide isolated from the complex aggregated in a similar fashion as the freshly prepared A $\beta 1-42$ (Figure 6A); after $24 \mathrm{~h}, 27 \%$ of the peptide remained in solution (in comparison with $23.5 \%$ of the fresh A $\beta 1-42$ control) whereas that value dropped to $4.4 \%$ after $72 \mathrm{~h}$. In addition, its $C D$ spectrum was almost identical to that of the fresh A $\beta 1-42$. The secondary structure calculated from the molar ellipticity plots revealed that no substantial conformational changes had been induced in the peptide by the presence of apoJ. A $\beta 1-42$ either recovered from the complex or freshly prepared has predominantly $\beta$-sheet structure and possesses full capability to undergo aggregation (Figure 6).

Since the formation of the complex prevented the aggregation of $\mathrm{A} \beta 1-42$, we tested whether the interaction also had any influence on the susceptibility of the peptide to proteolytic degradation. $\mathrm{A} \beta 1-40$ and $\mathrm{A} \beta 1-42$, either native or complexed to apoJ, were subjected to cleavage by trypsin, chymotrypsin and plasmin. Enzymic degradation was evaluated by immunoblot analysis, using monoclonal $6 \mathrm{E} 10$ followed by densitometric evaluation of the resulting fluorograms. Time-course experiments indicated that when complexed to apoJ, both A $\beta 1-40$ and A $\beta 1-42$ were more resistant to proteolysis. Chymotrypsin digestion is depicted in Figure 7; after 60 min of incubation at $37{ }^{\circ} \mathrm{C}$, only $20-25 \%$ of both peptides was not degraded by the enzyme whereas $65 \%$ of the apoJ-A $\beta 1-40$ complex and $85 \%$ of the apoJ-A $\beta 1-42$ complex remained undigested. Similar results were obtained with trypsin and plasmin. This protective effect was not seen in control experiments using human apoE or apoAI under the same conditions (results not shown).

The in vitro data presented above indicate a high-affinity binding between apoJ and the two main forms of the $\mathrm{A} \beta$ peptide, A $\beta 1-40$ predominantly found as the soluble $\mathrm{sA} \beta$ as well as in cerebrovascular amyloid deposits and A $\beta 1-42$ the main component of the parenchymal senile plaques. The biological importance of the interaction might reside (i) in the maintenance of the $\mathrm{sA} \beta$ solubility in biological fluids, a concept supported by the existence of the apoJ-sA $\beta$ complex in vivo in plasma [16] and CSF [15] and (ii) in the blood-to-brain transport of $\mathrm{sA} \beta$ across the blood-brain barrier. The latter is favoured by the in vivo 


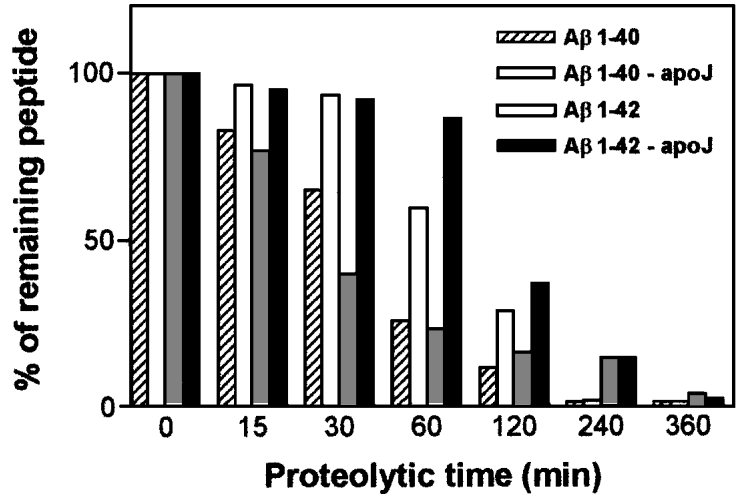

Figure 7 ApoJ protects $\mathrm{A} \beta$ peptides from proteolytic degradation

$A \beta 1-40$ and $A \beta 1-42$ in either the absence or the presence of apoJ were subjected to proteolytic cleavage using chymotrypsin $(1: 100 \mathrm{w} / \mathrm{w})$ under the conditions described in the Experimental section. After digestion, the remaining peptide was evaluated by immunoblotting with monoclonal $6 \mathrm{E} 10$ followed by peroxidase-labelled anti-mouse IgG and ECL. The resulting fluorograms were evaluated by densitometric scanning and image analysis. The percentage of the undigested peptide at each point of the time-course experiment is shown.

experiments performed in guinea pigs that indicate the existence of a specific mechanism at the blood-brain barrier that facilitates the capillary sequestration and transport of $\mathrm{A} \beta 1-40$ when complexed to apoJ [26,27], presumably mediated by the receptor for apoJ, gp330 (megalin) [33-35]. Since the apoJ affinities for $\mathrm{A} \beta 1-40$ and $\mathrm{A} \beta 1-42$ are very close (2.0 and $4.5 \mathrm{nM}$ respectively) it would be expected that apoJ would mediate a similar transport for $\mathrm{A} \beta 1-42$ linking $\mathrm{AD}$ to several types of systemic amyloidosis where the soluble amyloid precursor is normally found in the circulation [9]. Whether this is only important for the transport mechanism or might sustain a still unknown biological activity of $\mathrm{sA} \beta$ remains to be determined.

We have previously reported the co-localization of $\mathrm{sA} \beta$ with apoJ-containing HDL3 and very-HDL in plasma [16]. HDL particles are composed of $54-57 \%$ proteins (primarily apoAI and apoAII) and 43-46\% lipids, mainly esterified cholesterol and phospholipids [36]. Besides apoAI and apoAII, other plasma apolipoproteins are associated to these lipoprotein particles, among them apoE, apoJ, apoC, apoD and apoAIV. ApoJ is mainly bound to apoAI [37,38], although the presence of apoAI is not strictly necessary for apoJ to circulate, as demonstrated by the finding of normal levels of apoJ in patients deficient in apoAI (Tangier disease) [39]. Under physiologic conditions, apoJ in its native HDL lipidic environment is fully active to interact with $\mathrm{sA} \beta$; however, the influence that each component of the lipoprotein particle may exert in the interaction between apoJ and $\mathrm{sA} \beta$ in pathologic situations is not known, particularly those conditions that result in a modification of the relative ratio of the different constituents. The co-localization of apoJ with apolipoproteins with known binding activity for $\mathrm{A} \beta$ peptides (apoE isoforms [18,23], apoAI and apoAII [19]) in the same lipoprotein particle suggests a potential competition mechanism for the apoJ-A $\beta$ peptides interaction. In addition, the presence of other plasma proteins that interact with $\mathrm{A} \beta$ peptides (ACT [20] and TTR [21]) might further influence the binding activity. Our in vitro competitive inhibition studies with many of these isolated $\mathrm{A} \beta$-binding proteins suggest that under physiologic concentrations, the apoJ-A $\beta$ complex formation will take place. Taking into consideration the large carrier concentration excess $(1000 \times$; low $\mu \mathrm{M}$ versus low $\mathrm{nM})$, it would be expected that all the sA $\beta$ would be complexed to apoJ. However, a more accurate picture of the amount of $\mathrm{sA} \beta$ that circulates free and/or complexed to apoJ in physiologic as well as in pathologic situations would require the appropriate quantification of both components in different biological fluids.

In summary, the results presented here indicate that (i) a saturable and specific high-affinity binding interaction between apoJ and peptides homologous to the main forms of $\mathrm{sA} \beta(\mathrm{A} \beta 1-40$ and $\mathrm{A} \beta 1-42)$ can be demonstrated in vitro, (ii) the complex formation significantly prevents peptide polymerization and aggregation, and (iii) once the complex is formed, peptides became resistant to proteolytic degradation. The data suggest that the interaction described herein may preclude sA $\beta$ aggregation in biological fluids and point to a protecting role of apoJ for complexed $\mathrm{A} \beta$ species.

Supported by National Institutes of Health grants AG08721, AG05891, AR02594, AG10491 and AG10953, and by the Metropolitan Life Foundation Award for Medical Research.

\section{REFERENCES}

1 Wisniewski, T., Ghiso, J. and Frangione, B. (1994) Neurobiol. Aging 15, 143-152

2 Masters, C. L., Simms, G., Weinman, N. A., Multhaup, G., McDonald, B. L. and Beyreuther, K. (1985) Proc. Natl. Acad. Sci. U.S.A. 82, 4245-4249

3 Selkoe, D. J., Abraham, C. R., Podlisny, M. B. and Duffy, L. K. (1986) J. Neurochem. 146, 1820-1834

4 Wisniewski, T., Lalowski, M., Levy, E., Marques, M. R. F. and Frangione, B. (1994) Ann. Neurol. 35, 245-246

5 Prelli, F., Castaño, E. M., Glenner, G. G. and Frangione, B. (1988) J. Neurochem. 51, 648-651

6 Seubert, P., Vigo-Pelfrey, C., Esch, F., Lee, M., Dovey, H., Davis, D., Sinha, S., Schlossmacher, M., Whaley, J., Swindlehurst, C., McCormack, R., Wolfert, R., Selkoe, D., Lieberburg, I. and Schenk, D. (1992) Nature (London) 359, 325-327

7 Busciglio, J., Gabuzda, D. H., Matsudaira, P. and Yankner, B. A. (1993) Proc. Natl. Acad. Sci. U.S.A. 90, 2092-2096

8 Vigo-Pelfrey, C., Lee, D., Keim, P., Lieberburg, I. and Schenk, D. B. (1993) J. Neurochem. 61, 1965-1968

9 Castaño, E. and Frangione, B. (1991) Brain Pathol. 1, 263-271

10 Hilbich, C., Kisters-Woike, B., Reed, J., Masters, C. L. and Beyreuther, K. (1991) J. Mol. Biol. 218, 149-163

11 Burdick, D., Soreghan, B., Kwon, M., Kosmoski, J., Knauer, M., Henschen, A., Yates, J., Cotman, C. and Glabe, C. (1992) J. Biol. Chem. 267, 546-554

12 Hilbich, C., Kisters-Woike, B., Reed, J., Masters, C. L. and Beyreuther, K. (1994) J. Mol. Biol. 228, 460-473

13 Snyder, S., Ladror, U., Wade, W., Wang, G., Barrett, L., Matayoshi, E., Huffaker, K., Krafft, G. and Holzman, T. (1994) Biophys. J. 67, 1216-1228

14 Wisniewski, T., Castaño, E. M., Ghiso, J. and Frangione, B. (1993) Ann. Neurol. 34, 631-633

15 Ghiso, J., Matsubara, E., Koudinov, A., Choi-Miura, N.-H., Tomita, M., Wisniewski, T. and Frangione, B. (1993) Biochem. J. 293, 27-30

16 Koudinov, A., Matsubara, E., Frangione, B. and Ghiso, J. (1994) Biochem. Biophys. Res. Commun. 205, 1164-1171

17 Matsubara, E., Frangione, B. and Ghiso, J. (1995) J. Biol. Chem. 270, 7563-7567

18 Wisniewski, T. and Frangione, B. (1992) Neurosci. Lett. 135, 235-238

19 Strittmatter, W. J., Saunders, A. M., Schmechel, D., Pericak-Vance, M., Enghild, J., Salvesen, G. S. and Roses, A. D. (1993) Proc. Natl. Acad. Sci. U.S.A. 90, 1977-1981

20 Golabek, A., Marques, M. A., Lalowski, M. and Wisniewski, T. (1995) Neurosci. Lett. 191, 79-82

21 Ma, J., Yee, A., Brewer, H. B., Das, S. and Potter, H. (1994) Nature (London) 372 92-94

22 Schwarzman, A. L., Gregori, L., Vitak, M., Lyubski, S., Strittmatter, W. J., Enghilder, J. J., Bhasin, R., Sioverman, J., Weisgraber, K. H., Coyle, P. K., Zagorski, M. G., Talafous, J., Eisenberg, M., Saunders, A. M., Roses, A. D. and Goldgaber, D. (1994) Proc. Natl. Acad. Sci. U.S.A. 91, 8368-8372

23 Sanan, D. A., Weisgraber, K., Huang, D. Y., Saunders, A., Schmechel, D., Wisniewski, T., Frangione, B., Roses, A. D. and Strittmatter, W. J. (1994) J. Clin. Invest. 94, 860-869 
24 Wisniewski, T., Castaño, E. M., Golabek, A., Vogel, T. and Frangione, B. (1994) Am. J. Pathol. 145, 1030-1035

25 Castaño, E., Prelli, F., Wisniewski, T., Golabek, A., Kumar, A., Soto, C. and Frangione, B. (1995) Biochem. J. 306, 599-604

26 Zlokovic, B., Ghiso, J., Mackic, J., McComb, J., Weiss, M. and Frangione, B. (1993) Biochem. Biophys. Res. Commun. 197, 1034-1040

27 Zlokovic, B., Martel, C. L., Mackic, J. B., Matsubara, E., Wisniewski, T., Frangione, B. and Ghiso, J. (1994) Biochem. Biophys. Res. Commun. 205, 1431-1437

28 Choi-Miura, N.-H., Tobe, T., Hara, K., Yoshida, H. and Tomita, M. (1990) J. Immunol. Meth. 131, 159-163

29 Kim, K. S., Miller, D. L., Sapienza, V. J., Chen, C. M. J., Bai, C., Grundke-lqbal, I., Currie, J. and Wisniewski, H. M. (1988) Neurosci. Res. Commun. 2, 121-130

30 Bryan, J. K. (1977) Anal. Biochem. 78, 513-519

31 Perczel, A., Park, K. and Fasman, G. D. (1992) Anal. Biochem. 203, 83-93

32 Barrow, C. J., Yasuda, A., Kenny, P. T. and Zagorsky, M. G. (1992) J. Mol. Biol. 225, 1075-1093

Received 10 October 1995/18 January 1996; accepted 5 February 1996
33 Kounnas, M. Z., Loukinova, E. B., Stefansson, S., Harmony, J. A., Brewer, B. H., Strickland, D. K. and Argraves, W. S. (1995) J. Biol. Chem. 270, 13070-13075

34 Saito, A., Pietromonaco, S., L00, A. K. C. and Farquhar, M. G. (1994) Proc. Natl. Acad. Sci. U.S.A. 91, 9725-9729

35 Zlokovic, B., Martel, C., Matsubara, E., McComb, G., Zheng, G., McCluskey, R., Frangione, B. and Ghiso, J. (1996) Proc. Natl. Acad. Sci. U.S.A. 93, 4229-4232

36 Scanu, A. M., Edelstein, C. and Keim, P. (1975) in The Plasma Proteins. Structure, Function, and Genetic Control (Putnam, F. W., ed.), vol. I, pp. 317-391, Academic Press, New York

37 DeSilva, H. V., Stuart, W. D., Duvic, C. R., Wetterau, J. R., Ray, M. J., Ferguson, D. G., Albers, H. W., Smith, W. R. and Harmony, J. A. (1990) J. Biol. Chem. 265 , 13240-13247

38 Jenne, D. E., Lowin, B., Peitsch, M. C., Bottcher, A., Schmitz, G. and Tschopp, J. (1991) J. Biol. Chem. 266, 11030-11036

39 Choi-Miura, N.-H., Sakamoto, T., Ohtaki, S., Nakamura, H., Ishizawa, S. and Takagi, Y. (1993) Clin. Exp. Immunol. 93, 242-247 